\title{
Effect of local heating of the rat testis on the levels in interstitial fluid of a putative paracrine regulator of the Leydig cells and its relationship to changes in Sertoli cell secretory function*
}

\author{
J. M. S. Bartlett and R. M. Sharpe \\ MRC Reproductive Biology Unit, Centre for Reproductive Biology, 37 Chalmers Street, \\ Edinburgh EH3 9EW, U.K.
}

\begin{abstract}
Summary. Rat testes were exposed to heat $\left(43^{\circ} \mathrm{C}\right)$ for 15 or $30 \mathrm{~min}$ to induce moderate or severe disruption of spermatogenesis, respectively. Over 3-42 days after treatment, testicular morphology and weight, the serum concentrations of FSH and the concentrations in interstitial fluid of testosterone, androgen-binding protein (ABP) and a factor(s) capable of stimulating Leydig cell testosterone secretion were monitored. Moderate seminiferous tubule damage induced by $15 \mathrm{~min}$ heat exposure caused a small decrease $(20 \%)$ in testicular weight, but did not affect the other measures, other than transiently. In contrast, after exposure of testes to heat for 30 min there was a major and progressive decline in testicular weight throughout the experimental period, reaching $39 \%$ of control values by 42 days. In these animals, the serum concentrations of FSH were significantly increased $(P<0.01)$ throughout the period of study as also where the serum and interstitial fluid concentrations $\mathrm{ABP}(P<0.05-0.01)$ and levels of interstitial fluid factor $(P<0 \cdot 01)$.

It is concluded that the activity of the interstitial fluid factor(s) can be increased by inducing severe but selective disruption of spermatogenesis, whereas moderate disruption has no effect. Moreover, as ABP secretion into interstitial fluid was increased after severe but not moderate disruption, this suggests that in such animals proportionately more ABP may be secreted via the base of the Sertoli cell. The parallel changes in activity of the interstitial fluid factor(s) and concentrations of ABP in interstitial fluid also provides further circumstantial evidence that these products may have a common (Sertoli cell) origin.
\end{abstract}

\section{Introduction}

The existence of a factor or factors produced within the testis which modulate Leydig cell testosterone production has now been clearly demonstrated (Parvinen et al., 1984; Janecki et al., 1985; Sharpe, 1986). These factors are thought to act primarily by altering Leydig cell responsiveness to LH (Sharpe, 1986). The physiological relevance of such factors is as yet uncertain, although their potential importance is clear in relation to maintenance of the high levels of intra-testicular testosterone required for quantitatively normal spermatogenesis.

Previous studies involving a factor(s) in rat testicular interstitial fluid have shown that, when added in vitro to Percoll-purified Leydig cells, interstitial fluid is capable of markedly increasing testosterone production in response to LH or hCG (Sharpe \& Cooper, 1984; Sharpe, 1985). Furthermore interstitial fluid obtained from rats treated with the Leydig cell toxin ethane dimethane sulphonate

\footnotetext{
*Reprint requests to Dr R. M. Sharpe.
} 
(EDS) or which have been made experimentally cryptorchid have been shown to contain elevated amounts of the interstitial fluid factor (Sharpe et al., 1986b, c). Activity of this factor has also been shown to be increased during puberty in the rat (Sharpe et al, 1986a), suggesting that this factor may be important physiologically.

Whilst indicating that experimental disruption of the seminiferous epithelium leads to increased levels of this interstitial fluid factor, the aforementioned studies have so far not related changes in the activity of this factor(s) to the degree of damage induced or to changes in Sertoli cell secretory function. These were the primary objectives of the present investigation. The method chosen was short-term exposure of the testis to heat, as this has been used previously by a number of workers to study testicular function and it is evident that the duration of exposure to heat determines the degree of testicular damage induced (Chowdhury \& Steinburger, 1964, 1970; Jegou et al., 1984). We have therefore compared the temporal effects of moderate and severe disruption of spermatogenesis induced by local heating of the testis on activity of the interstitial fluid factor(s) and related such findings to the levels in interstitial fluid of testosterone and a known Sertoli cell product, androgen binding protein (ABP).

\section{Materials and Methods}

Animals and treatments. All animals were adult Sprague-Dawley rats from our own colony and were aged between 75 and 90 days at treatment. All animals were anaesthetized with $50 \mathrm{mg}$ pentobarbitone sodium/ $\mathrm{kg}$ (Sagatal: May \& Baker Ltd, Dagenham, U.K.). Control animals were allowed to recover with no further treatment. Heat treatment was applied by immersion of the testes in a waterbath at $43^{\circ} \mathrm{C}$. Animals were strapped into a frame using surgical tourniquets, ensuring that the animal was supported with sufficient slack for breathing, and then the lower

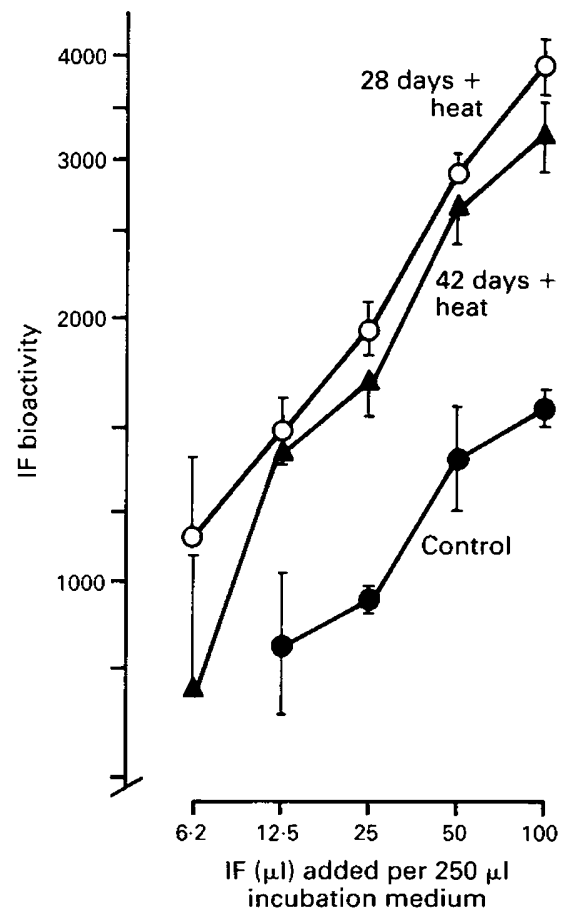

Fig. 1. Dose-dependent enhancement of hCG-stimulated Leydig cell testosterone production by pools of interstitial fluid (IF) from control rats and animals 28 and 42 days after exposure of testes to heat for $30 \mathrm{~min}$ (i.e. IF bioactivity). Results have been expressed as the increment ( $\mathrm{ng} / 10^{6}$ cells $/ 20 \mathrm{~h}$ ) in testosterone production above that stimulated by $5 \mathrm{~nm}$-hCG alone. Each point is the mean \pm s.d. of triplicate incubations. 
third of the abdomen of the animal was immersed in the water bath. The temperature of the bath was monitored continually throughout the treatment period but did not vary detectably from $43^{\circ} \mathrm{C}$. Animals were introduced to the bath and the testes immersed for 15 or $30 \mathrm{~min}$. Animals were killed at various times after treatment, and at each time point age-matched controls were also killed.

Collection of body fluids and tissues and hormonal measurements. Trunk blood was collected at death, and the serum was separated and stored at $-20^{\circ} \mathrm{C}$ before the measurement of testosterone (Corker \& Davidson, 1978) and FSH (Fraser \& Sandow, 1977) using materials supplied by the NIAMDDK, Bethesda, MD, U.S.A. Interstitial fluid was collected as described previously (Sharpe \& Cooper, 1983), the volume was recorded and aliquants were taken for testosterone and ABP determination and assessment of levels of the interstitial fluid factor. The testosterone concentration in interstitial fluid was measured as described previously (Sharpe \& Bartlett, 1985), after dilution in M199 with Hanks salts (Pharmacia Ltd, Hounslow, U.K.). Concentrations of rat androgen-binding protein (ABP) in interstitial fluid and serum were determined using a previously validated radioimmunoassay (Gunsalus et al., 1978, 1981), provided in kit form by NIAMDDK, U.S.A. In addition, it was demonstrated that samples of interstitial fluid and serum gave dilution curves which paralleled each other and those of the standard curve (data not shown). For all assays, samples were measured in a single assay and the intra-assay CV was $<10 \%$. The limits of detection $\left(90 \% \mathrm{~B} / \mathrm{B}_{0}\right)$ were $11 \mathrm{pg}, 2 \mathrm{ng}$ and $3.5 \mathrm{ng}$ for the testosterone, ABP and FSH assays, respectively.

Concentrations of the interstitial fluid factor(s) were determined by measuring the ability of charcoai-stripped testicular interstitial fluid from individual rats to enhance testosterone production by Percoll-purified Leydig cells stimulated with a supramaximal dose $(5 \mathrm{~nm})$ of hCG (see Sharpe et al., 1986a, b). Because of the small volumes of interstitial fluid available, samples from individual animals were assayed at only a single dilution. Previous studies have shown the dose-dependence of the stimulatory effects of interstitial fluid on testosterone production in vitro (Sharpe \& Cooper, 1984; Sharpe et al., 1986a, b), and for the present studies it was confirmed that pools of interstitial fluid from various treatment groups gave log dose-response curves that were parallel to each other (Fig. 1). Therefore, it was considered valid to use single-point determinations of the 'bioactivity' of individual interstitial fluid samples as this approach is obviously superior to the use of pools of interstitial fluid in which between-animal variation (which is considerable) would be masked. All interstitial fluid samples were assayed together with the same preparation of Leydig cells. Under the present conditions, no major effects of interstitial fluid on Leydig cell numbers were detected (our unpublished data).

Testicular morphology. At each time point, the testes of 2-3 rats exposed to 15 and 30 min heat were fixed by vascular perfusion via the thoracic aorta, and processed for light microscopy as described elsewhere (Kerr \& Sharpe, 1985). Semi-thin $(1 \mu \mathrm{m})$ sections were examined using a Zeiss photomicroscope fitted with oil-immersion objectives.

Statistics. Data were analysed using nested analysis of variance (ANOVA), and Dunnet's $t$ test to determine variation from control.

\section{Results}

\section{Testicular morphology and weight}

In rats exposed to $43^{\circ} \mathrm{C}$ for $15 \mathrm{~min}$, examination of sections from perfusion-fixed testes confirmed in general the detailed analyses of Chowdhury \& Steinberger $(1964,1970)$. In such testes selective and stage-specific damage to leptotene, zygotene and pachytene spermatocytes was the most obvious early change and, in many tubule cross-sections at 3 and 7 days, these cells were either degenerating or absent. Degenerating pachytene spermatocytes were still noted in some tubules at 14 days but, in general, the germ cells missing at later time points were those that would have derived from the damaged or missing spermatocytes, i.e. at 14 days many tubules lacked round spermatids while at 21 days predominantly elongate spermatids were missing. This pattern of selective germ cell damage was reflected in the relatively small decreases that occurred in testicular weight at $7-42$ days after exposure to $15 \mathrm{~min}$ heat (Fig. $2 \mathrm{a}$ ).

In rats exposed to $30 \mathrm{~min}$ heat, damage to the germ cells was more widespread but was still selective. As well as changes comparable to those described above for $15 \mathrm{~min}$ heat exposure, the major additional early effect was on round spermatids, while elongate spermatids appeared to be unaffected. At 3 days most tubules at stages $I$ and $V$ of the spermatogenic cycle contained either few or no round spermatids and many of these tubules also lacked spermatocytes. Tubules at stages VI to VIII did contain round spermatids but lacked pachytene spermatocytes completely. At 7 days, a picture similar to that at 3 days was evident, although in addition there was the widespread appearance of giant multinucleated cells and large vacuoles in the epithelium of many tubules. 

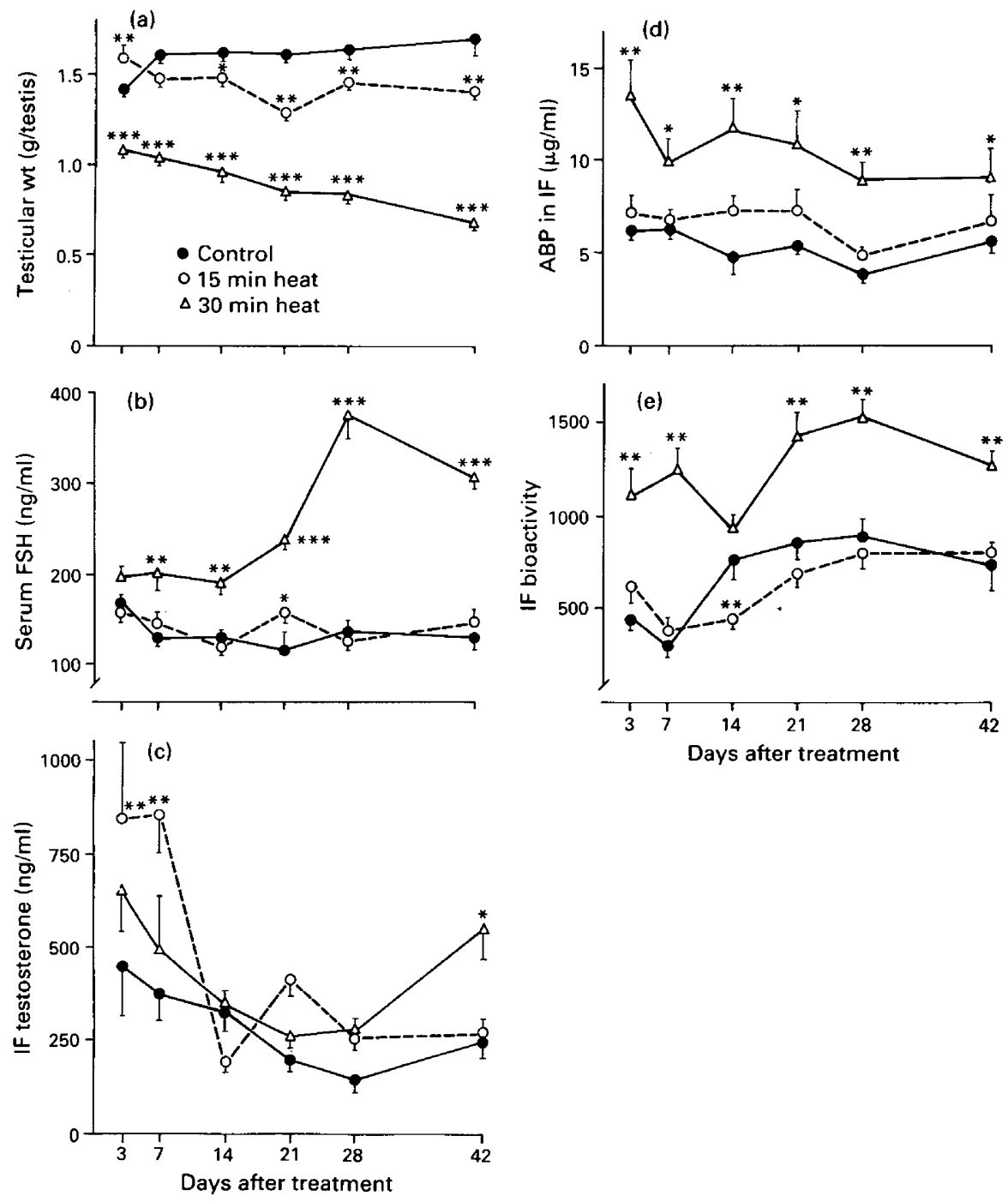

Fig. 2. Effect of exposure of testes to heat for 15 or $30 \mathrm{~min}$ on (a) testicular weight, (b) serum concentrations of FSH, (c) concentration of testosterone in testicular interstitial fluid, (d) concentration of androgen binding protein in testicular interstitial fluid (IF), and (e) IF bioactivity expressed as the increment (ng/10 cells $/ 20 \mathrm{~h}$ ) in hCG-stimulated testosterone production by Percoll-purified Leydig cells, induced by the addition of charcoal-stripped IF from individual rats. Each point is the mean \pm s.e.m. for $8-20$ rats/group. ${ }^{*} P<0.05,{ }^{* *} P<0.01$, ${ }^{* * *} P<0.001$ when compared with respective control value.

Elongate spermatids were still present in the majority of seminiferous tubules and they were sometimes the only germ cells other than spermatogonia to be present. Retained sperm heads at stages IX-XII were also noted occasionally. At 14 days, tubule diameter was clearly reduced and the seminiferous epithelium reduced in depth. Some tubules contained only Sertoli cells and spermatogonia but most also contained primary spermatocytes, often clearly in subnormal numbers. Round and elongate spermatids were absent from $80 \%$ or more of tubules, some of which still contained giant cells and large vacuoles. Beyond 14 days after exposure to $30 \mathrm{~min}$ heat, there was a progressive recovery towards normal and by 42 days spermatogenesis appeared qualitatively normal in about $25 \%$ of tubules. In a further $40-50 \%$ of tubules there were clearly subnormal germ cell 
numbers (particularly of elongate spermatids), although all of the appropriate germ cell types were present; some of these tubules still contained occasional large vacuoles. About $25 \%$ of tubules showed little or no resumption of spermatogenesis and contained mainly Sertoli cells and spermatogonia only.

The more extensive damage to the seminiferous epithelium in rats exposed to $30 \mathrm{~min}$ heat was reflected in a substantial $(23 \%)$ reduction in testicular weight as early as 3 days after treatment (Fig. 2a). Thereafter, testicular weight continued to decline steadily, reaching its lowest level (39\% of control) at 42 days.

At the light microscope level there were no obvious changes to the Leydig cells or to other components of the testis in any of the treatment groups, although detailed morphometric analysis is needed to confirm this impression. The interstitial fluid-filled intertubular spaces were clearly distended at 14 days and later after exposure to heat, especially in the 30 -min treatment group, and this was reflected in the volumes of interstitial fluid recovered at these times (see below).

\section{Serum FSH}

Serum concentrations of FSH in animals exposed to heat for $15 \mathrm{~min}$ did not vary significantly from control values, except at 21 days after treatment when values were slightly elevated $(P<0.05)$ over control. In animals exposed to heat for $30 \mathrm{~min}$, FSH concentrations were elevated above controls within 3 days of treatment and this reached statistical significance at 7 days $(P<0.01$; Fig. 2b). Thereafter, serum FSH values remained significantly $(P<0.01-0.001)$ higher than control values throughout the experimental period, reaching a peak value ( $360 \%$ of controls) at 28 days after treatment (Fig. 2b).

\section{Serum and interstitial fluid concentrations of testosterone}

In animals exposed to heat for 15 or $30 \mathrm{~min}$ the serum concentrations of testosterone did not vary significantly from the respective controls at any of the time points (data not shown). However, the mean ( \pm s.d.) concentrations of testosterone in serum were higher at $3(7.3 \pm 4.0 \mathrm{ng} / \mathrm{ml} ; \mathrm{N}=9)$ and 7 days $(5 \cdot 4 \pm 1.6 \mathrm{ng} / \mathrm{ml} ; \mathrm{N}=9)$ after exposure to 15 -min heat than were the overall values in controls $(2 \cdot 9 \pm 2 \cdot 2 \mathrm{ng} / \mathrm{ml} ; \mathrm{N}=8)$, and these were the only two times at which the interstitial fluid concentrations of testosterone were raised significantly in 15-min heat-treated animals (see Fig. 2c). At all other times after exposure to 15 -min heat there was no significant change in the concentrations of testosterone in interstitial fluid, and in rats exposed to heat for $30 \mathrm{~min}$ the only change evident was a significant $(P<0.05)$ increase at 42 days after treatment $($ Fig. $2 \mathrm{c})$.

\section{Serum and interstitial fluid concentrations of $A B P$}

After exposure to heat for $15 \mathrm{~min}$, ABP concentrations in interstitial fluid were increased at all times compared to controls, although at no time did this effect reach statistical significance (Fig. 2d). Similarly, no significant change in the serum values of ABP was observed in these animals (data not shown).

In animals exposed to heat for $30 \mathrm{~min}$, concentrations of ABP in interstitial fluid were increased significantly $(P<0.05-0.01)$ within 3 days of treatment, both with respect to control animals and rats exposed to heat for $15 \mathrm{~min}$. Values remained significantly elevated throughout the experimental period (Fig. 2d). In this group, serum ABP concentrations were also consistently higher than in controls throughout the observation period (overall mean \pm s.d. levels for controls $=$ $1 \cdot 1 \pm 0.5 \mu \mathrm{g} / \mathrm{ml}, \mathrm{N}=48$; overall mean levels for 30 -min heat-treated rats $=1.7 \pm 0.5 \mu \mathrm{g} / \mathrm{ml}$, $\mathrm{N}=53 ; P<0.001$ ). 


\section{Interstitial fluid 'bioactivity'}

Amounts of an interstitial fluid factor which stimulates Leydig cell testosterone production in vitro were assessed (i.e. bioactivity). After exposure to heat for $15 \mathrm{~min}$, no significant change in interstitial fluid bioactivity, with respect to controls, was observed, apart from a slight but significant reduction in levels at 14 days after treatment (Fig. 2e). In contrast, after exposure to heat for 30 min bioactivity was increased significantly $(P<0 \cdot 01)$ within 3 days of treatment and, thereafter, remained elevated throughout the period of observation, although at 14 days this increase was small and statistically insignificant (Fig. 2e). Bioactivity in controls varied during this study with rather low values observed at Days 3 and 7 . This was most probably the consequence of exposure to anaesthetic on Day 0, as pentobarbitone is known to reduce LH secretion severely, which then rebounds to high levels in the recovery period and raised $\mathrm{LH}$ concentrations will reduce interstitial fluid bioactivity for at least several days (Sharpe et al., 1986c).

\section{Interstitial fluid volume}

To ensure that any increase in observed values for testosterone and ABP concentrations in interstitial fluid or interstitial fluid bioactivity were not simply consequences of a reduction in interstitial fluid volume, this value was assessed in all animals. The volume of interstitial fluid in control rats did not vary significantly between times and, overall, the recovered volume per testis was $73 \pm 36 \mu \mathrm{l}$ per testis (mean \pm s.d., $N=48$ ). In rats exposed to heat for 15 or 30 min, interstitial fluid volume remained unchanged from control values at 3 and 7 days, but thereafter the mean recovered volume was increased with respect to controls, the magnitude of this mean increase varying from 40 to $188 \%$. This increase was consistently greater for rats exposed to $30 \mathrm{~min}$ than to 15 min heat, and at $14,21,28$ and 42 days after exposure to 30 min heat the mean \pm s.d. $(\mathrm{N}=8-10$ rats per time point) recovered volumes of interstitial fluid were $156 \pm 54,181 \pm 49,210 \pm 78$ and $131 \pm 71 \mu \mathrm{l} /$ testis respectively; all of these values were significantly different from the overall control value $(P<0.001)$ and from the respective control value at each of the time points $(P<0.05-0.001)$.

\section{Discussion}

Using short-term exposure of the rat testis to heat we have compared the effects of moderate and severe impairment of spermatogenesis on the amounts of an interstitial fluid factor(s) which stimulates Leydig cell testosterone secretion. We have shown that, after exposure of testes to heat for $30 \mathrm{~min}$, interstitial fluid amounts of this factor(s) are increased, a finding which confirms earlier studies in which raised values of this factor(s) have been identified following testicular damage induced by cryptorchidism or testosterone withdrawal (Sharpe et al., 1986a, b). In the present study, it has been demonstrated that induction of an increase in levels of this interstitial fluid factor is related to the degree of tubule damage caused by heat exposure, because after 15-min exposure no increase (when compared to control animals) in the activity of the factor(s) was detected. Furthermore, increased activity of the factor(s) was associated with increased secretion of ABP into interstitial fluid, which provides further circumstantial evidence that the factor is derived from the Sertoli cell. Finally, we have shown increased secretion of ABP into interstitial fluid after severe seminiferous tubule damage, which adds weight to previous findings that have suggested that there is a proportional change in the direction of secretion of ABP in such situations.

Previous studies on heat treatment of the rat testis (Steinberger \& Dixon, 1959; Chowdhury \& Steinberger, 1964, 1970; Jegou et al., 1984) have shown that selected and stage-related damage to germ cells in the seminiferous epithelium occurs after immersion of the testes in water at $43^{\circ} \mathrm{C}$ for $15 \mathrm{~min}$, and this was confirmed in the present study. Testicular weight declined after heat treatment 
for $15 \mathrm{~min}$, accompanied by only a marginal rise in serum FSH concentrations (Fig. 2b), confirming the findings of Jegou et al. (1984). In contrast, extending the period of heat treatment to $30 \mathrm{~min}$ produced more widespread damage to germ cells in the epithelium, leading to a sustained decline in testicular weight (Fig. 2a). This decrease was mirrored by an increase in the serum concentrations of FSH, as is seen in other states in which the seminiferous epithelium is severely damaged (e.g. cryptorchidism, efferent duct ligation: Risbridger et al., 1981; Jegou et al., 1984).

While the difference in effect of 15- and 30-min heat exposure was as predicted, it allows comparison of the consequences of severe and moderate disruption of the seminiferous epithelium produced via the same mechanism. Neither short- nor long-term exposure of the rat testis to heat, and the subsequent severe damage in the latter case, produced major or sustained changes in intratesticular concentrations of testosterone (Fig. 2c). Indeed, after heat treatment for 30 min, testicular weights declined to $39 \%$ of control values before there was any significant increase in interstitial fluid concentrations of testosterone. This suggests that, whilst testosterone is known to be essential for the maintenance of spermatogenesis, changes in its concentrations in interstitial fluid, and particularly serum, are not a good indicator of testicular damage. In addition to these findings, we have observed that induction of moderate impairment of spermatogenesis by exposure of testes to heat for $15 \mathrm{~min}$ had no significant effect on the interstitial fluid values of ABP or the serum concentrations on FSH, whilst induction of severe impairment of spermatogenesis by heat treatment for 30 min increased both serum FSH and the serum and IF concentrations of ABP significantly (Fig. 2d). Similarly, the activity of a factor(s) in interstitial fluid which modulates Leydig cell function in vitro was increased after exposure of the testes to heat for 30 but not $15 \mathrm{~min}$ (Fig. 2e).

The present finding that severe seminiferous tubule damage induced by heat exposure is associated with increased activity of the interstitial fluid factor(s) also confirms similar observations made after the induction of severe tubule damage by cryptorchidism or treatment with EDS (Sharpe $e t$ al., 1986a, b). However, the present findings are the first to indicate that a fairly severe degree of tubule damage is required to induce such an increase, findings which further suggest that this factor(s) is of some physiological significance.

This interstitial fluid factor(s) is thought to originate from the Sertoli cell because its activity in interstitial fluid is increased considerably in testes lacking germ cells (Sharpe \& Cooper, 1984) or Leydig cells (Sharpe et al., 1986b). The present observation that increased activity of the factor(s) was always associated with increased secretion of ABP into interstitial fluid provides at least circumstantial support for this possibility, particularly as parallel changes in the interstitial fluid concentrations of ABP and the activity of the factor(s) occur in at least 2 other situations in which tubule damage is induced by means other than exposure of the testes to heat (R. M. Sharpe \& J. M. S. Bartlett, unpublished data).

In the normal rat testis, ABP is secreted bi-directionally by the Sertoli cell into the lumen of the seminiferous tubules and, via the base of the Sertoli cell, into testicular interstitial fluid (Gunsalus et al., 1980; 1981). ABP is secreted in two forms (I and II) which differ slightly in their carbohydrate content, and the relative proportion of the two forms secreted into the tubule lumen (approximately equal amounts of forms I and II) is different from that secreted into interstitial fluid and thence into the bloodstream (form II predominates over form I by 3- to 4-fold) (Cheng et al., 1984, 1986). In situations in which major seminiferous tubule dysfunction is present in rats as a consequence of hypophysectomy (Gunsalus et al., 1980, 1981) or selected genetic abnormalities (Cheng et al., 1984), then the serum concentrations of ABP are increased. As the ABP in serum derives predominantly from that secreted into testicular interstitial fluid (Lobl et al., 1983; Becker et al., 1984), this suggests that ABP secretion into interstitial fluid is increased in these two types of experimental rats.

The present results are therefore in good agreement with these earlier studies in showing that induction of major seminiferous tubule damage by exposure to heat for 30 min results in an increase in the serum concentrations of ABP, with a particularly marked increase in the interstitial fluid values of ABP. It could be argued that this change is not the result of increased basal secretion 
of ABP by the Sertoli cell but rather increased 'leakage' as a consequence of damage to the inter-Sertoli cell tight junctions. While this possibility cannot be excluded completely, two pieces of evidence strongly oppose this interpretation. First, when seminiferous tubule damage has been induced by cryptorchidism or by testosterone withdrawal, the interstitial fluid concentrations of ABP are also significantly increased (unpublished data) and similar changes can be inferred to occur after hypophysectomy and in rats with genetically determined tubule damage (see references above). It seems unlikely that damage to the inter-Sertoli cell tight junctions would occur in such diverse situations and this situation is reinforced by a second piece of evidence relating to the proportion of forms I and II of ABP in serum. It is clear that, before closure of the inter-Sertoli cell tight junctions (i.e. prepubertally), roughly equal proportions of forms I and II of ABP are secreted into the blood (via interstitial fluid) and into the tubule lumen, whereas in adulthood form II predominates over form $I$ in the blood (see above, and Cheng et al., 1984). Disruption of the inter-Sertoli cell tight junctions should therefore lead to 'leakage' of ABP from the seminiferous tubules into interstitial fluid, resulting in a reduction in the ratio of form $I I /$ form $I$ in the blood. This does not occur, because in infertile rats with major seminiferous tubule dysfunction the ratio of the two forms of ABP present in serum is comparable to that in normal adult rats (Cheng et al., 1984). From such evidence it therefore seems most likely that the increase in interstitial fluid concentrations of $\mathrm{ABP}$ in situations of seminiferous tubule damage is the consequence of increased secretion via the base of the Sertoli cell.

The finding of increased levels of ABP in interstitial fluid in the testes of rats with seminiferous tubule dysfunction also suggests that, in such animals, there is a major shift in the direction of secretion of ABP, as it is clear from studies using short-term unilateral efferent duct ligation that ABP secretion into the tubule lumen is decreased considerably after induction of cryptorchidism (Hagenas \& Ritzen, 1976) or local heating (Jegou et al., 1984). This conclusion is entirely consistent with previous observations in which the concentrations of ABP in serum (i.e. derived from interstitial fluid) were found to be increased in experimental animals in which the total testicular and epididymal contents of ABP were reduced drastically (Gunsalus et al., 1980, 1981). It is therefore possible that the absolute rate of production of ABP by the Sertoli cell is decreased after damage to the seminiferous epithelium but that a far greater proportion than normal is secreted via the base of the Sertoli cell into testicular interstitial fluid and from there into the bloodstream. The physiological significance of this change in the directional secretion of ABP is unknown but it reinforces the suggestion (Gunsalus et al., 1981) that measurement of ABP (and other secretory products of the Sertoli cell) in testicular interstitial fluid and/or serum may be useful for monitoring changes in the functional activity of the Sertoli cells in vivo.

We thank Mr Denis Doogan and Miss Irene Cooper for skilled help; and the NIAMDDK, U.S.A., for the provision of materials for the radioimmunoassay for FSH and ABP. This work was carried out whilst J.M.S.B. was in receipt of a Journal of Reproduction \& Fertility Fellowship for studies in Reproduction.

\section{References}

Becker, R.R., Gunsalus, G.L., Musto, N.A. \& Bardin, C.W. (1984) The epididymis contributes minimally to serum androgen-binding protein in the rat: a whole body kinetic study. Endocrinology 114, 2354-2360.

Cheng, C.Y., Gunsalus, G.L., Musto, N.A. \& Bardin, C.W. (1984) The heterogeneity of rat androgen binding protein in serum differs from that in testis and epididymis. Endocrinology 114, 1386-1394.

Cheng, C.Y., Gunsalus, G.L., Morris, I.D., Turner, T.T. \& Bardin, C.W. (1986) The heterogeneity of rat androgen binding protein ( $\mathrm{ABP}$ ) in the vascular compartment differs from that in the testicular tubular lumen. Further evidence for bidirectional secretion of rABP. J. Androl. 7, 175-179.

Chowdhury, A.K. \& Steinberger, E. (1964) A quantitative study of the effect of heat on germinal epithelium of rat testes. Am. J. Anat. 115, 509-524.

Chowdhury, A.K. \& Steinberger, E. (1970) Early changes in the germinal epithelium of rat testes following exposure to heat. J. Reprod. Fert. 22, 205-212. 
Corker, C.S. \& Davidson, D.W. (1978) Radioimmunoassay of testosterone in various biological fluids without chromatography. J. Steroid Biochem. 9, 373-374.

Fraser, H.M. \& Sandow, J. (1977) Gonadotrophin release by a highly active analogue of $\mathrm{LHRH}$ in rats immunised against LHRH. J. Endocr. 74, 291-296.

Gunsalus, G.L., Musto, N.A. \& Bardin, C.W. (1978) Immunoassay of androgen binding protein in blood: a new approach for the study of the seminiferous tubule. Science, N.Y. 200, 65.66.

Gunsalus, G.L., Musto, N.A. \& Bardin, C.W. (1980) Bidirectional release of a Sertoli cell product, androgen binding protein, into the blood and seminiferous tubule. In Testicular Development, Structure and Function, pp. 291-297. Eds A. Steinberger \& E. Steinberger. Raven Press, New York.

Gunsalus, G.L., Larrea, F., Musto, R.R., Becker, R.R., Mather, J.P. \& Bardin, C.W. (1981) Androgen binding protein as a marker for Sertoli cell function. $J$. Steroid Biochem. 15, 99-106.

Hagenas, L. \& Ritzen, E.M. (1976) Impaired Sertoli cell function in experimental cryptorchidism. Molec. cell. Endocr. 4, 25-35.

Janecki, A., Jakubowiak, A. \& Lukaszyk, A. (1985) Stimulatory effect of Sertoli cell secretory products on testosterone secretion by purified Leydig cells in primary culture. Molec. cell. Endocr. 42, 227-233.

Jegou, B., Laws, A.O. \& de Kretser, D.M. (1984) The effects on testicular function induced by short-term exposure of the rat testis to heat: further evidence for interaction of germ cells, Sertoli cells and Leydig cells. Int. J. Androl. 7, 244-257.

Kerr, J.B. \& Sharpe, R.M. (1985) Follicle-stimulating hormone induction of Leydig cell maturation. Endocrinology 116, 2592-2604.

Lobl, T.J., Musto, N.A., Gunsalus, G.L. \& Bardin, C.W. (1983) Medroxyprogesterone acetate has opposite effects on the androgen binding protein concentration in serum and epididymis. Biol. Reprod. 29, 697-712.

Parvinen, M., Nikula, H. \& Huhtaniemi, I. (1984) Influence of rat seminiferous tubules on Leydig cell testosterone production in vitro. Molec. cell. Endocr. 37, 331-336.
Risbridger, G.P., Kerr, J.B., Peake, R.A., Rich, K.A. \& de Kretser, D.M. (1981) Temporal changes in Leydig cell function after induction of bilateral cryptorchidism. J. Reprod. Fert. 63, 415-423.

Sharpe, R.M. (1985) Intratesticular regulation of testosterone secretion: comparison of the effects and interactions of hCG, an LHRH agonist and testicular interstitial fluid on Leydig cell testosterone secretion in vitro. Molec. cell. Endocr. 41, 247-255.

Sharpe, R.M. (1986) Paracrine control of the testis. Clinics Endocr. Metab. 15, 185-207.

Sharpe, R.M. \& Bartlett, J.M.S. (1985) Intratesticular distribution of testosterone in rats and the relationship to the concentrations of a peptide that stimulates testosterone secretion. J. Reprod. Fert. 74, 223-236.

Sharpe, R.M. \& Cooper, I. (1983) Testicular interstitial fluid as a monitor for changes in the intratesticular environment in the rat. J. Reprod. Fert. 69, 125-135.

Sharpe, R.M. \& Cooper, I. (1984) Intratesticular secretion of a factor(s) with major stimulatory effects on Leydig cell testosterone secretion in vitro. Molec. cell. Endocr. 37, 159-168.

Sharpe, R.M., Doogan, D.G. \& Cooper, I. (1986a) Intratesticular factors and testosterone secretion: the role of $\mathrm{LH}$ in relation to changes during puberty and experimental cryptorchidism. Endocrinology 119, 2089-2096.

Sharpe, R.M., Kerr, J.B., Cooper, I. \& Bartlett, J.M.S. (1986b) Intratesticular factors and testosterone secretion: the effect of treatment with EDS and the induction of seminiferous tubule damage. Int. $J$. Androl. 9, 285-298.

Sharpe, R.M., Kerr, J.B., Fraser, H.M. \& Bartlett, J.M.S. (1986c) Intratesticular factors and testosterone secretion: effect of treatments which alter the level of testosterone within the testis. J. Androl. 7, 180-189.

Steinberger, E. \& Dixon, W.J. (1959) Some observations on the effect of heat on the testicular germinal epithelium. Fert. Steril. 10, 578-595.

Received 29 September 1986 